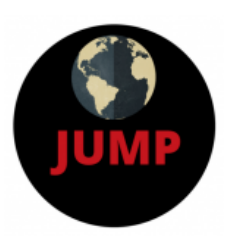

\author{
(C) Journal of Underrepresented and Minority Progress \\ Volume 5, Issue 1 (2021), pp. 26-40 \\ ISSN: 2574-3465 Print/ ISSN: 2574-3481 Online \\ http://ojed.org/jump
}

\title{
Lost in the Host: The Struggle of a Syrian Refugee Family in Urban Schools with a Child Suffering from Undiagnosed PTSD Symptoms
}

\author{
Naglaa Mohamed \\ University of Toledo, USA
}

\begin{abstract}
The Syrian refugee crisis has put schools worldwide under pressure to meet the unique needs of refugee children, many of whom suffer from undiagnosed post-traumatic stress disorder (PTSD) symptoms. Using thematic analysis on open-ended interview data, the present case study examined the experience of a Syrian refugee family who recently arrived in the United States and their experiences at two different school districts. An analysis of the findings indicates the need for trauma-informed schools that provide tailored interventions and counseling to help refugee students overcome their traumatic experiences. This study also demonstrates a need for a revision to the Individuals with Disabilities Education Act's (IDEA) definition of an emotional disturbance to specifically include students who have experienced trauma. The four emerging themes that support these recommendations were positions that aggravate PTSD symptoms, schools' negligence in accommodating for a new culture, an ineffective academic approach (sink or swim), and social isolation due to lack of acceptance. While this study focused on a Syrian refugee mother and her children, their experiences may advise a planned path for this growing population.
\end{abstract}

Keywords: Syrian refugees, PTSD, trauma-informed schools, IDEA 


\section{INTRODUCTION}

Since the Syrian conflict escalated in March 2011, hundreds of thousands of Syrian families fled to the US to escape the war and enrolled their children in public schools. The recent refugee crisis has put schools worldwide under pressure to expand educational facilities to accommodate the unique needs of those children, many of whom suffer from undiagnosed post-traumatic stress disorder (PTSD) symptoms. According to the results of a systematic review conducted by Fazel et al. (2005), among refugees resettled in Western countries, 9\% of them presented PTSD symptoms (in a range from $3 \%$ to $44 \%$, depending on group characteristics), $5 \%$ major depression, $4 \%$ anxiety disorder, and $2 \%$ psychotic disorder. In 2019, Peconga \& Thøgersen investigated cross-sectional data for 8,176 adult Syrian refugees resettled in 10 different countries, and reported prevalence rates of $43.0 \%$ (range: 23.4 $83.4 \%$ ) for post-traumatic stress, $40.9 \%$ (range: $20-44.1 \%$ ) for depression, and $26.6 \%$ (range: $19.30-31.8 \%$ ) for anxiety morbidity. They also stated that refugees were at considerable risk of developing common mental disorders, including depression, anxiety, and post-traumatic stress disorder. Syrian refugees could be over 10 times more likely to develop posttraumatic stress and other disorders than the general population (Peconga \& Thøgersen, 2019).

Given the extent of the problems facing Syrian children, this case study presents a Syrian refugee family's experiences at two urban schools: a public school within the stipulated geographical zone of their home address and a charter school. This study shed light on the hardship these young adults encountered and may increase policymakers' understanding of the psychological needs of this population to ensure their wellbeing.

\section{LITERATURE REVIEW}

The psychological wellbeing of young people has been a major worldwide public health concern (Saxena, 2007). Perkins et al. (2018) emphasized how children are vulnerable to mental health issues during times of conflict: refugee children may frequently experience negative thoughts, nightmares, and thoughts of death, and are more prone to mental disorders, including depression, post-traumatic stress disorder (PTSD), and anxiety (Perkins et al., 2018; Salloum, 2015; Steel et al., 2009).

The UN High Commissioner for Refugees (2019) reported at least 79.5 million people around the world have been forced to flee their homeland. This number includes nearly 26 million refugees, around half of whom are under the age of 18 , creating the largest number of refugees and 
the worst humanitarian crisis since the Second World War and putting great emphasize on the role of schools as some of this population transitions into new schools within the United States. Perkins et al. (2018) conducted a study on 492 Syrian refugees between the ages of 8-15 and found that Syrian children experienced a current and looming mental health crisis that needs to be addressed.

Refugees are a highly vulnerable population due to their exposure to traumatic events such as torture, rape, murder, or even massacre in their home countries. They are also likely to experience danger and potentially traumatic events during the course of their plight (Nicholl \& Thompson, 2004); Acarturk et al., 2018). When refugees arrive at their host locations, many already suffer from psychological and physical impairments from traumatic events that have impacted their quality of life (Nickerson et al., 2017). In addition to these traumatic experiences, refugees arrive to face resettlement challenges including a new language and culture; disrupted or limited education; distraught family networks; poverty and insecure housing; and negative stereotypes and discrimination (Block et al., 2014).

Through their research in Australian schools, Taylor \& Sidhu (2012) found that school systems that adopt policies emphasizing growth, school safety, skill development, and supportive relationships had greater success educating refugee students. These approaches are also associated with greater levels of student school engagement and achievement (Zengaro, Ali, \& Zengaro, 2016). Schools are often the first safe haven that refugee children encounter on their search for stability and acceptance. Schools can provide the ideal setting to conduct interventions to address the mental health needs of this population. Supportive education environments that meet the needs of this growing population can promote self-esteem and resilience and avoid their social isolation (Kovacev \& Shute, 2004).

\section{PROBLEM STATEMENT}

Sullivan and Simonson (2016) argued that schools have a critical role in improving mental health and socio-emotional functioning and relieving depression symptoms from refugee students who have been exposed to trauma in their home country. Research has proven that tailored interventions could reduce the psychological impact of traumatic events (Khamis, 2019; Tol et al., 2011). Intervention specialists are trained to provide these interventions to students suffering from mental health concerns under special education services. Specifically, Sullivan and Simonson (2016) reported that cognitive behavioral therapy (CBT) interventions that have been conducted by intervention specialists and 
school counselors showed consistent outcomes in decreasing depression and developing coping skills. However, intervention specialists were required to work with only students who receive special education services.

Winder (2015) argued that the current definition of "Emotional Disturbance," as outlined by the Individuals with Disabilities Education Act's (IDEA), does not address the specific needs of children who were exposed to traumatic experience; instead of being identified to receive special education services, they are often left undetected without services that would help them benefit academically. According to IDEA (2004), Emotional Disturbance is a condition exhibiting one or more of the following characteristics over a long period of time and to a marked degree that adversely affects a child's educational performance:

a) An inability to learn that cannot be explained by intellectual, sensory, or health factors.

b) An inability to build or maintain satisfactory interpersonal relationships with peers and teachers.

c) Inappropriate types of behavior or feelings under normal circumstances.

d) A general pervasive mood of unhappiness or depression.

e) A tendency to develop physical symptoms or fears associated with personal or school problems.

The definition incorporates schizophrenia, and excludes students who are socially maladjusted unless it is determined that a student's social maladjustment is due to their emotional disturbance and is not just a function of their behavior. The current definition neglects the needs of many students who have faced traumatic experiences and their desperate needs for counseling and interventions. Oehlberg (2008) argued that adding a subcategory to the definition to include students who have faced particular trauma in their life would create "trauma-sensitive" schools, encouraging a paradigm shift with minimum cost in the way schools approach the education process.

\section{RESEARCH PURPOSE}

The purpose of this phenomenological qualitative case study is to present the first-year experiences of a Syrian refugee child suffering from undiagnosed PTSD symptoms at an urban school in Midwestern US, as narrated by her mother. The study aimed to gain insights about the unique needs of Mona, a Syrian female student with undiagnosed PTSD symptoms that were not addressed by school professionals, and the required amendment needed to consider the rights of this population under special education services. 


\section{RESEARCH QUESTIONS}

This study explores the following research question: What are the first year experiences of a Syrian refugee child suffering from undiagnosed PTSD symptoms at an urban school in Midwestern US?

\section{Qualitative Research}

\section{RESEARCH METHOD}

According to Domegan and Fleming (2007), qualitative research is especially useful when little is known about the problem at hand because it is explored at a complex level. A key characteristic of qualitative research is that it helps researchers understand people and how their backgrounds shape their experiences (Myers, 2009).

\section{Phenomenological Case Study}

The aim of case study research is to look for explanations and gain understanding of the phenomenon. As stated by Yin (2009), "A case study is an empirical inquiry that investigates a contemporary phenomenon in depth and within its real-life context, especially when the boundaries between phenomenon and context are not clearly evident" (p. 18). This qualitative case study followed a phenomenological approach. According to van Manen (2014), "Phenomenology is the way of access to the world as we experience it pre-reflectively. Pre-reflective experience is the ordinary experience that we live in and that we live through for most, if not all, of our day-to- day existence" (p. 26). Through interviews, phenomenology explores common experiences of participants to identify the essence of the experience (Creswell, 2013). Founded by German philosopher Edmund Husserl (Spinelli, 1989), phenomenology is considered a vital philosophy when researching to discover individuals' personal experiences (McLeod, 2001).

\section{Participant Information}

The research participant, Salma, is an Arabic-speaking mother of two children: Omar, a 17-year-old boy, and Mona, a 15-year-old girl. Salma's family evacuated their country due to war and initially escaped to Jordan where they waited to evacuate to the US, where they earned Refugee status. As a result of these conditions, Salma did not arrive with any documentation for her family, including birth certificates, transcripts, or vaccination records. Salma's children joined the same high school; however, her daughter, Mona, suffered symptoms of PTSD that were not experienced by her son, Omar. I was introduced to Salma after Mona had enrolled in her third public school and after Omar's graduation. Salma did not have much to 
share about the new school other than her family moving closer to it because Omar could no longer drive Mona to the previous charter school. Salma's children's yearlong experiences at their first US school, however, warranted attention. According to Salma, there was no attempt at understandable communication with the family; they were communicated with as native speakers of English - a language that no one in the family comprehended.

\section{Open-ended Interview}

\section{DATA COLLECTION}

Bachman and Schutt (2008) explained that qualitative researchers employ intensive interviewing exclusively through open-ended questions, without systematic observation of the study participants in their natural setting. Hearing Salma's response in her own words and in her native language was an effective tool to convey her feelings in this study.

Through open-ended interview questions, I collected data in Arabic, Salma's native language, and gave her frequent opportunities to elaborate on or provide more relevant information.

\section{RESEARCH ETHICS}

Prior to the initiation of any research activities, I obtained approval for human subject research and verification of translation consistency, as required by the University's Institutional Review Board (IRB). To ensure confidentiality, I assigned a pseudonym to the participant and her children to guarantee their anonymity (Sieber, 1998). Additionally, English copies of the informed consent form and interview questions were provided to the school district.

Participation in this research was voluntary, without compulsion or obligation. The local school district that I partnered with recruited Salma, among others. I selected Salma because of the uniqueness of the experience she shared. Prior to beginning the interview, Salma read and signed an informed consent form in Arabic, which provided her with information about the purpose of the study, as well as a brief description of the procedure, possible benefits, risks of voluntary participation, confidentiality terms, and my contact information. I also explained to Salma that she had the right to stop participating at any time with no consequences.

\section{FINDINGS}

After careful analysis of Salma's responses during the interview, four underlying themes emerged about the family's experience prior to their move to a new school district. This is provided below. 


\section{Positions that Aggravate PTSD Symptoms}

When asked in the interview to describe the interactions her family has had with her children's school, Salma, in Arabic, shared a unique experience that was a mix of hope and pain while her children were trying to adapt to their new environment.

My daughter, Mona, has been suffering from flashbacks, eating disorders, and frightening thoughts since the war in Syria. I noticed that there are gaps in her memory and that she's always anxious when leaving the family even for a short amount of time. Mona doesn't want to be around friends or socialize with anyone. The teachers ignored all of this although these symptoms are noticeable at school too and significantly impact my daughter's ability to learn. I remember Mona coming home and telling me about a fire drill that happened at her school...there were police officers and fire trucks outside of the school and her anxiety was triggered because no one had explained what was happening. Once the other students started evacuating, my daughter had flashbacks of the war in our home country and experienced an elevated heart rate as she looked for her brother.

\section{Schools' Negligence in Accommodating for a New Culture}

Salma shared that the school did not prepare her children to understand the school policy, as the family had arrived after the orientation given to all freshmen. Salma stated that this added to her children's stress and created difficulties for them, recalling,

The school had not even given my children any type of orientation to explain dress code, assigned lockers, or show them where classes are located, or how to communicate with the main office, libraries, counselors, and deans. My children would waste a lot of time trying to reach the right classes with their limited English and lack of support from the people around them...There was an incident in Mona's class, where a student reported that his cellphone was stolen, and a school officer came to fetch students and investigate the matter. I remember my daughter telling me that she was very scared when the officer tried to touch her. Mona started feeling very depressed, unwelcome, and lonely at the school and cried to stay home from school.

Salma indicated that this experience impacted her daughter as well as the whole family. 


\section{Ineffective Academic Approach (Sink or Swim)}

Salma could not justify the placement of her Arabic-speaking children in classes taught in English. She stated in a distressed tone, "Although my children had no knowledge of English, they were still placed in English classes with no accommodations made to assist them, and my children ended up receiving failing grades in their classes... one ESL class was not enough." When I asked Salma about the way her children would respond to their teachers, she shared that Omar and Mona were very quiet and sat in the corner of the room, not comprehending any instruction. Salma also explained that her children spent their class time trying to watch everyone's body language to help them to make assumptions or create a mental scenario on what might be happening around them.

\section{Social Isolation due to Lack of Acceptance}

Salma shared other recollections with anguish about her daughter, Mona, being bullied at the school because of her headscarf and limited English.

There was a clear lack of acceptance towards us and there had been several altercations when other students mocked Mona for her limited English and for wearing a hijab (headscarf)... she was the only girl with a hijab. The school staff found my children's Arabic names too hard for them to pronounce and they opted out of using them; instead, they referred to my children as "the refugees," the first English word that my whole family learned during the evacuation process. This frustrated my children because it called them out further... like they didn't already feel like outsiders. Students were very hostile towards my children and more specifically towards our religion as they were bulling my daughter because of her hijab.

Salma explained that the lack of acceptance towards Mona led to Mona's social isolation because she felt unwelcome by her peers. Salma reported that this further exasperated her daughter's trauma, depression, insomnia, and increased her hypervigilance. After Salma's several failed attempts to solve problems at the school and help build cultural bridges, she decided to move her children to a new school district.

\section{The New School Experience}

When I asked Salma to describe how the new school she moved to helped her children, she said, "The charter school used my children's native language as a tool to reach out to them and further their instruction." She 
explained that during the first year, Salma's children received one-on-one instruction in chunks for all subjects from an ESL teacher. The teacher isolated the needed vocabulary in each class, giving Mona and Omar time to study them before testing their knowledge. At the end of the first year, Salma's children started feeling more confident in their speaking, reading, and writing abilities. They moved on to regular classes for their next year, receiving the same instruction among their peers. Salma's children felt safer in the new school environment due to the presence of a diverse culture that included other Muslim and Arab students. Salma reported that Mona started to be less anxious and calmer compared to her demeanor at the previous school; however, the new school still overlooked Mona's PTSD symptoms and her need for interventions.

\section{DISCUSSION}

It should first be noted that from Salma's narration, I found that only Salma's daughter suffered from PTSD symptoms although both children experienced the same plight. This is supported by research in that although males are more likely to experience traumatic events, females are more likely to develop PTSD (Wittchen et al., 2009). Alpak et al. (2014) also described PTSD among Syrian refugees as a significant mental health problem, especially among female refugees. This was the case with Mona, who displayed episodes of depression and wanted to stay home from school often.

The impact of Mona's cultural orientation on her PTSD symptoms must also be analyzed. In their study, Starck et al. (2020) explored the relationship between cultural orientation, traumatic events, and depression in female refugees from several countries including Syria. They found that the effect of traumatic events was not influenced by cultural orientation. This means that Mona's symptoms were not a result of how well she integrated into her new culture.

Miller et al. (2010) emphasized that daily stressors such as living in unsafe places, a lack of access to basic needs, and the absence of social support partially exacerbate the effect of war exposure in developing mental health problems. Mona's school life added its own hardship, enabling her to relive her trauma everyday. One could argue that because of the inexplicit definition of emotional disturbance and Mona's trauma not being enough to make her eligible to receive special education services, the lack of tailored interventions by a specialist furthered her symptoms and left her lost in her new host environment. This calls for an increased focus on adequate mental health support for this population. 
Due to Salma's ignorance of her daughter's rights to a free appropriate public education (FAPE) under the Individuals with Disabilities Education Act (Turnbull, Huerta, \& Stowe, 2009; Yell, 2012), Salma did not request an evaluation for Mona and was not aware that she should or could initiate this process. Educating parents about special education services is the district's responsibility. Professionals who neglect to provide sufficient information about services and rights and do not meet parents' need for increased communication and cultural sensitivity, create even more barriers to a successful partnership (Sullivan, 2009; Connery, 1987; Harry, 2002; Matuszny, 2004).

In addition, Salma believed that the school's "sink or swim" approach limited her children's access to equitable educational opportunities. In an article by the Policy Insights from Behavioral and Brain Sciences, Robinson-Cimpian, Thompson, \& Umansky (2016) determined that current education policies limit English learners' access to equitable educational opportunities and put them at a disadvantage compared to their monolingual peers.

To address the language barriers experienced by culturally and linguistically diverse (CLD) children, Palmer, et al. (2007) suggest the following strategies that schools with recently immigrated Arab students could use: (a) effective instructional practices regarding students transitioning from Arabic to English, i.e., strengthening students' Arabic reading strategies for word recognition and fluency, (b) recognizing the cultural aspects of Arabic and the transition from it, i.e., pairing the student with an Arabic-speaking mentor, and (c) a brief analysis of the differences in composition, i.e., providing scaffolding to mitigate the Arabic-to-English transition. Scaffolding in learning is breaking up content into chunks and using secondary supports to understand each chunk (Walqui, 2006). Yigzaw (2012) argued that using scaffolding in English learners' native language would enhance their ability to learn the second language. Such concrete suggestions, many of which were informally followed at Mona's second school, allow teachers and administration to better grasp the transition experienced by the students as they learn the English language and adapt to school in the United States.

The Federal Educational Rights and Privacy Act (FERPA, 1974) forbade schools from disclosing most confidential student information to non-school personnel, including government agents. This federal law applies to all educational institutions and agencies that receive federal funding, which include all public and charter schools. Therefore, referring to 
Mona and Omar as "refugees" was not only demeaning to them, but also in direct violation of FERPA.

Research has also shown that it is not uncommon for CLD families to move schools because of the difficulties they experience (Rivera et al., 2016). For example, after several failed attempts to solve problems at the school and help build cultural bridges, Salma decided to move her children to a new school that better accommodated Mona and Omar's needs for individualized instruction.

From the analysis of the participant's answers to the open-ended interview questions, the four themes that emerged answered the research question by underlining the negative and challenging first year experiences of a Syrian refugee child suffering from undiagnosed PTSD symptoms at an urban school. Although generalization from individual case study's findings is impractical, this case study raised a concurrent question of how long it would take for a radical pursuit of social justice pedagogy to become a governing factor in children's education - not only in agreeing with, but also in implementing and adopting it. As stated by Steeley and Lukacs (2015), "Unfortunately, U.S. schools have a legacy of marginalizing immigrant populations in schools" (p. 29).

\section{CONCLUSION}

This case study analysis offered evidence that challenges the prevailing assumptions of a "one size fits all" approach and calls for special education identification and services provision. Policymakers should revise IDEA's definition of emotional disturbance to add a subcategory focused on trauma to serve many students who have been excluded from services due to the ambiguous nature of the current definition. Moreover, schools should not increase refugee students' stress and challenge their insecurities; instead, they should provide mental, social, and emotional learning interventions for these children by implementing preventative and/or rehabilitation programs. By understanding and analyzing children's unique needs after such traumatic experience, school personnel are likely to better respond to Syrian refugees with an improved agenda that ensures their wellbeing.

Additionally, many refugee students are bullied due to their race or peripheral status in their new country (Closs et al., 2001). Hek (2005) recommends that schools adopt anti-bullying programs to promote a healthy environment of inclusive education that respects all students and does not eliminate a specific group. Providing equitable educational opportunities by engaging English learners instead of leaving them at one corner would enhance their inclusion in their new learning environment. 
Creating trauma-informed schools in response to the need for interventions and counseling for this neglected population will relieve their stress and enable them to recover from their trauma in their new environment. Oehlberg (2008) finds that creating trauma-informed schools requires administrative buy-in and support, trauma-sensitive classroom practices, positive and restorative responses to behavior, policy and procedure changes, teacher and staff professional development, and strong cross-system collaboration among school staff and mental health professionals. Trauma-informed schools mean reducing student bullying, behavioral outbursts, dropouts, and school suspensions. This will improve the school's overall climate and students' academic achievement. This case study suggests the need for change efforts in creating a more humanizing, welcoming and caring learning setting.

\section{LIMITATIONS AND RECOMMENDATIONS FOR FUTURE RESEARCH}

This study presented limitations that were the result of the limited number of participants who met the research criteria.

Further research should expand recruitment to include participants of different cultural backgrounds, genders, and religions. Researchers may also want to explore the experiences of families of children in various grade levels. Additional research should also be conducted to study the practices and policies that schools have implemented to effectively engage refugee families and foster their children's mental and emotional wellbeing. It is vital to report on the interventions that can help relieve refugee students' PTSD symptoms and ensure their success.

\section{REFERENCES}

Acarturk, C., Cetinkaya, M., Senay, I., Gulen, B., Aker, T., \& Hinton, D. (2018). Prevalence and predictors of posttraumatic stress and depression symptoms among Syrian refugees in a refugee camp. The Journal of Nervous and Mental Disease, 206(1), 40-45.

Alpak, G., Unal, A., Bulbul, F., Sagaltici, E., Bez, Y., Altindag, A., . . Savas, H. A. (2014). Post-traumatic stress disorder among Syrian refugees in Turkey: A cross-sectional study. International Journal of Psychiatry in Clinical Practice, 19(1), 45-50. doi:10.3109/13651501.2014.961930

Bachman, R., \& Schutt, R. K. (2008). Fundamentals of research in criminology and criminal justice. Los Angeles: Sage Publications.

Block, K., Cross, S., Riggs, E. \& Gibbs, L. (2014). Supporting schools to create an inclusive environment for refugee students International. The Journal of Inclusive Education, 18(12), 1337-1355. 
Closs, A., Stead, J., Arshad, R., \& Norris, C. (2001). School peer relationships of 'minority' children in Scotland. Child: Care, health and development, 27(2), 133-148. DOI: $10.1177 / 0038040711402361$

Connery, A. R. (1987). A description and comparison of Native American and Anglo parents' knowledge of their handicapped children's educational rights (Navajo). Dissertation Abstracts International, 48(04), 898. (UMI No. 8715278).

Creswell, J. (2007). Qualitative inquiry and research design: Choosing among five traditions. (2nd ed.). Thousand Oaks, CA: Sage.

Creswell, J. (2013). Research Design: Qualitative, quantitative, and mixed methods. (4th ed.). Thousand Oaks, CA: Sage.

Domegan, C., \& Fleming, D. (2007). Marketing research in Ireland (3rd ed.). Dublin: Gill MacMillan.

Family Educational Rights and Privacy Act (FERPA), 20 U.S.C. § 1232g; 34 C.F.R. Part 99 (1974).

Fazel, M., Wheeler, J., \& Danesh, J. (2005). Prevalence of serious mental disorder in 7000 refugees resettled in western countries: A systematic review. The Lancet, 365(9467), 1309-1314.

Harry, B. (2002). Trends and issues in serving culturally diverse families of children with disabilities. Journal of Special Education, 36(3), 131-138, 147.

Hek, R. (2005). The role of education in the settlement of young refugees in the UK: The experiences of young refugees. Practice, 17(3), 157-171.

Khamis, V. (2019). Posttraumatic stress disorder and emotion dysregulation among Syrian refugee children and adolescents resettled in Lebanon and Jordan. Child Abuse \& Neglect, 89, 29-39.

Kovacev, L. \& Shute, R. (2004). Acculturation and social support in relation to psychosocial adjustment of adolescent refugees resettled in Australia. International Journal of Behavioral Development, 28(3), 259-267.

Matuszny, R. M. (2004). American Indian parental involvement and needs in the individual education plan process: A collective exploratory case study of two Midwestern public school districts. Unpublished doctoral dissertation, The Pennsylvania State University, State College.

McLeod, J. (2001). Qualitative research in counselling and psychotherapy. London, UK: Sage.

Miller, K. E., \& Rasmussen, A. (2010). War exposure, daily stressors, and mental health in conflict and post-conflict settings: Bridging the divide between trauma-focused and psychosocial frameworks. Social Science \& Medicine, 70(1), 7-16.

Myers, M. D. (2009). Qualitative research in business \& management. London: Sage.

Nicholl, C., \& Thompson, A. (2004). The psychological treatment of post-traumatic stress disorder (PTSD) in adult refugees: A review of the current state of psychological therapies. Journal of Mental Health, 13(4), 351-362. 
Nickerson, A., Liddell, B., Asnaani, A., Carlsson, J. M., Fazel, M., Knaevelsrud, C., et al. (2017). Trauma and Mental Health in Forcibly Displaced Populations. International Society for Traumatic Stress Studies.

Oehlberg, B. (2008). Why schools need to be trauma informed. Trauma \& Loss: Research \& Interventions, 8(2), 12-15.

Palmer, B. C., El-Ashry, F., Leclere, J. T., \& Chang, S. (2007). Learning from Abdullah: A case study of an Arabic-speaking child in a U.S. school. The Reading Teacher, 61, 8-17.

Peconga, E. K., \& Høgh Thøgersen, M. (2019). Post-traumatic stress disorder, depression, and anxiety in adult Syrian refugees: What do we know? Scandinavian journal of public health, 1403494819882137.

Perkins, J. D., Ajeeb, M., Fadel, L., \& Saleh, G. (2018). Mental health in Syrian children with a focus on post-traumatic stress: a cross-sectional study from Syrian schools. Social Psychiatry and Psychiatric Epidemiology, 53(11), 1231-1239.

Rivera, C., Jimenez, B., Baker, J., Spies, T., Mims, P., \& Courtade, G. (2016). A culturally and linguistically responsive framework for improving academic and postsecondary outcomes of students with moderate or severe intellectual disability. Physical Disabilities: Education and Related Services, 35(2), 23-48.

Robinson-Cimpian, J., Thompson, K., \& Umansky, I. (2016). Research and policy considerations for English learner equity. Policy Insights from the Behavioral and Brain Sciences, 3(1), 129-137.

Salloum, A. (2015). Grief and trauma in children: An evidence-based treatment manual. New York, NY: Routledge, Taylor \& Francis Group.

Saxena, S., Thornicroft, G., Knapp, M., \& Whiteford, H. (2007). Resources for mental health: scarcity, inequity, and inefficiency. The Lancet, 370(9590), 878-889.

Sieber, J. E. (1998). Planning ethically responsible research. In L. Bickman \& D. J. Rog (Eds.), Handbook of applied social research methods (pp. 127-156). Thousand Oaks, CA: Sage.

Spinelli, E. (1989). The interpreted world: An introduction to phenomenological psychology. London: Sage Publication.

Starck, A., Gutermann, J., Schouler-Ocak, M., Jesuthasan, J., Bongard, S., \& Stangier, U. (2020). The relationship of acculturation, traumatic events and depression in female refugees. Frontiers in Psychology, 11, 906.

Steel, Z., Chey, T., Silove, D., Marnane, C., Bryant, R. A., \& Ommeren, M. V. (2009). Association of torture and other potentially traumatic events with mental health outcomes among populations exposed to mass conflict and displacement. Jama, 302(5), 537.

Steeley, S. L., \& Lukacs, K. (2015). Cultural and linguistic diversity and special education: A case study of one mother's experiences. International Journal of Special Education, 30(2), 20-31. 
Sullivan, A. L., \& Simonson, G. R. (2016). A systematic review of school based social- emotional interventions for refugee and war-traumatized youth. Review of Educational Research, 86(2), 503-530.

Sullivan, P. M. (2009). Violence exposure among children with disabilities. Clinical Child and Family Psychology Review, 12(2), 196-216.

Taylor, S. \& Sidhu, R. K. (2012). Supporting refugee students in schools: What constitutes inclusive education? International Journal of Inclusive Education, 16(1), 39-56.

Tol, W. A., Barbui, C., Galappatti, A., Silove, D., Betancourt, T. S., Souza, R., ... van Ommeren, M. (2011). Mental health and psychosocial support in humanitarian settings: linking practice and research. Lancet, 378(9802), $1581-1591$.

Turnbull, A., Huerta, N., \& Stowe, M. (2009). What every teacher should know about: The individuals with disabilities education act as amended in 2004. (2nd ed.). Upper Saddle River, NJ: Pearson.

UN High Commissioner for Refugees (UNHCR). (2019). Figures at a Glance. Retrieved from https://www.unhcr.org/figures-at-a-glance.html.

van Manen, M. (2014). Phenomenology of Practice: Meaning-giving methods in phenomenological research and writing. California: Left Coast Press.

Walqui, A. (2006). Scaffolding instruction for English language learners: A conceptual framework. International Journal of Bilingual Education and Bilingualism, 9(2), 159-180.

Winder, F. (2015). Childhood trauma and special education: Why the "IDEA" is failing today's impacted youth. Hofstra Law Review, 44(2).

Wittchen, H. U., Gloster, A., Beesdo, K., Schönfeld, S., and Perkonigg, A. (2009). Posttraumatic stress disorder: diagnostic and epidemiological perspectives. CNS Spectr. 14(1 Suppl. 1), 5-12.

Yell, M. L. (2012). Law and special education. (3rd ed.). Upper Saddle River, NJ: Pearson. Yigzaw, A. (2012). Impact of L1 use in L2 English writing classes. Ethiopian Journal of Education and Sciences, 8(1), 11-27.

Yin, R. K. (2009). Case study research: Design and methods (3rd ed.). Thousand Oaks, CA: Sage.

Zengaro, F., Ali, M., \& Zengaro, S. (2016). Academic and community identities: A study of Kurdish and Somali refugee high school students. Journal of Research Initiatives, 2(1).

NAGLAA MOHAMED, PhD, is an independent scholar in Ohio, who has an earned doctorate in special education and advocates for special education students and for social justice for minority students. Email: advocate4me@protonmail.com.

Manuscript submitted: July 1, 2020

Manuscript revised: December 14, 2020

Accepted for publication: March 5, 2021 